\title{
A laboratory module on radiometry, photometry and colorimetry for an undergraduate optics course
}

\section{Robert Polak}

Robert D. Polak, "A laboratory module on radiometry, photometry and colorimetry for an undergraduate optics course," Proc. SPIE 9289, 12th Education and Training in Optics and Photonics Conference, 92891F (17 July 2014); doi: 10.1117/12.2070524

SPIE Event: 12th Education and Training in Optics and Photonics Conference, 2013, Porto, Portugal 


\title{
A Laboratory Module on Radiometry, Photometry and Colorimetry for an Undergraduate Optics Course
}

\author{
Robert D. Polak \\ Department of Physics, Loyola University Chicago, Chicago, IL USA 60660
}

\begin{abstract}
The bachelor's degree in Physics at Loyola University Chicago requires both an upper-division course in Optics as well as a companion Optics Laboratory course. Recently, the laboratory course has undergone dramatic changes. Traditional weekly laboratories have been replaced with three laboratory modules, where students focus on a single topic over several weeks after which the students submit a laboratory report written in the style of a journal article following American Institute of Physics style manual. With this method, students are able to gain a deeper understanding of the specific topic areas of radiometry, photometry and colorimetry, lens design and aberrations, and polarization and interference while using industry-standard equipment and simulation software. In particular, this work will provide the details of the laboratory module on radiometry, photometry and colorimetry where students use a photoradiometer and integrating sphere to characterize the optical properties of an LCD monitor, light bulb and a fiber optic light source calculating properties such as luminous flux, luminous intensity, luminance, CIE color coordinates, NTSC ratio, color temperature and luminous efficacy.
\end{abstract}

Keywords: Optics Education, Photometry, Radiometry, Colorimetry

\section{INTRODUCTION}

Loyola University Chicago is one of the United States' largest Jesuit, Catholic Universities. Founded in 1870 as St. Ignatius College, Loyola's excellence in education has been consistently ranked by U.S. News and World Report among the "top national universities." Loyola offers a bachelor's degree in Physics and has recently grown into one of the largest bachelor's-only degree granting departments in the United States, averaging 21 graduates a year from the period from 2008 to 2010 [1] and graduating 30 students this spring. Our graduates pursue a wide range of opportunities after they graduate, including graduate studies in physics and engineering, professional studies in education and medicine, as well as joining the workforce as engineers, researchers and technicians in private companies, hospitals and government laboratories.

This growth has enabled the physics curriculum to be revamped, and an increased emphasis has been placed on advanced laboratory courses. Optics and its corresponding laboratory course, Optics Laboratory, are required courses for Physics majors and elective courses for Biophysics and Theoretical Physics and Applied Mathematics majors. Furthermore, all students at Loyola are required to take two writing-intensive courses, in which there is a variety of writing assignments integrated closely with the course curriculum. Optics Laboratory is a writing intensive course and is frequently the only writing intensive course that Physics majors take within the sciences.

To meet the future professional needs of the students as well as the requirements to be a writing-intensive course at Loyola, the laboratory work has been split into modules, where students focus on a single topic of optics in a laboratory environment over several weeks and publish a laboratory report written to meet the standards set by the American Institute of Physics Style Manual. Currently, there are three different modules within the laboratory course: a study of radiometry, photometry and colorimetry, a study of lens design, image formation and aberrations and a study in polarization, diffraction and interference. This work will cover the details of the first laboratory module including the experimental procedures, equipment used as well as less expensive alternatives and typical results collected and analyzed by the students.

12th Education and Training in Optics and Photonics Conference, edited by

Manuel F. P. C. Martins Costa, Mourad Zghal, Proc. of SPIE Vol. 9289, 92891F

(C) 2014 SPIE, OSA, IEEE, ICO · doi: 10.1117/12.2070524

Proc. of SPIE Vol. 9289 92891F-1 


\section{OPTICAL PERFORMANCE OF A MONITOR DISPLAY}

\subsection{Experimental Setup and Procedure}

The student's initial efforts will be to optically characterize the performance of a display. There are many possible options for the display, but we choose to use a liquid crystal display monitor interfaced with a computer using the Microsoft Windows Operating System. The display's performance is measured using a Topcon Photoradiometer SR3 with the data reported on another Windows OS computer using the Topcon CS-900 program. The SR3 has the advantage of reporting the radiance as a function of wavelength in intervals of $1 \mathrm{~nm}$, which is used later in this module. However, the SR3 is an expensive instrument and lower costs alternatives exist, including a Konica Minolta CS-100A chroma meter, an instrument that can read the luminance and CIE color coordinates of a surface.

The optical performance of the monitor is measured normal to the surface of the display. The monitor will be set up to display a full screen of a particular color, by using the Microsoft program Paint. Within Paint, custom colors can be created by clicking "Edit Colors", choosing the custom color button and entering the appropriate values for red, green and blue. Table 1 shows the values entered for each color tested. Once, the appropriate values have been entered, by using the "Fill with Color" icon, the entire area can be made a single color and using the "View Bitmap" selection, the entire monitor screen will show this single color. The students will measure the luminance and the 1931 and 1976 CIE color coordinates for each of the colors given in Table 1.

Table 1. The colors to be shown and measured on the monitor and the values entered in MS Paint to obtain those colors.

\begin{tabular}{|ll|}
\hline Display Color & Values Entered In MS-Paint \\
& \\
White & Red $=255 ;$ Green $=255 ;$ Blue $=255$ \\
Black & Red $=0 ;$ Green $=0 ;$ Blue $=0$ \\
Red & Red $=255 ;$ Green $=0 ;$ Blue $=0$ \\
Green & Red $=0 ;$ Green $=255 ;$ Blue $=0$ \\
Blue & Red $=0 ;$ Green $=0 ;$ Blue $=255$ \\
Gray Level 240 & Red $=240 ;$ Green $=240 ;$ Blue $=240$ \\
Gray Level 224 & Red $=224 ;$ Green $=224 ;$ Blue $=224$ \\
Gray Level 208 & Red $=208 ;$ Green $=208 ;$ Blue $=208$ \\
$\ldots$ & \\
Gray Level 16 & Red $=16 ;$ Green $=16 ;$ Blue $=16$ \\
\hline
\end{tabular}

\subsection{Analysis of the Display Measurements}

After the data is collected, the student will then analyze it by developing the key optical parameters used to specify a typical display. These parameters include the luminance, contrast ratio, NTSC Ratio, color temperature and gamma [2].

Luminance: The reported luminance of the display is the luminance of the display when displaying white. This is often referred as brightness in product specifications, which introduces the students to the often poor nomenclature used in optical specifications. A typical luminance for a monitor is 150 to 300 nits, while newer smart phone displays will have a typical luminance of 500 nits.

Contrast Ratio: The contrast ratio of the display is reported as the ratio of the luminance of the display when displaying white and the luminance of the display when displaying black. For liquid crystal displays, the contrast ratio is dependent on direction the display is viewed at. The maximum contrast ratio for liquid crystal displays are very near the normal to the display surface, but it can vary significantly with typical contrast ratios exceeding 250:1.

NTSC Ratio: The NTSC Ratio provides a single data point that gives an overall measure of the quality of the colors displayed by the monitor. Originally defined in 1953, the National Television System Committee specified the 1931 CIE color coordinates for red, green and blue images [3], forming a triangle when plotted. Because of the short lifetimes of the phosphors that could meet these requirements, most color televisions never met these specifications. The NTSC ratio is defined as the percentage of the area of the triangle formed by the color coordinates of the actual display's 
primary colors compared with the area of the triangle formed by the NTSC standard. This can be reported based on the 1931 CIE color coordinates of the 1976 CIE color coordinates. While the differences are usually minor, using the 1976 CIE color coordinates would be a more accurate representation of the qualities of the display's color as color differences as perceived by humans are more uniform in the 1976 system. Students are asked to report the NTSC ratios in both the 1931 and 1976 CIE color coordinate system.

Color Temperature: An alternative to reporting the CIE color coordinates of the display's white screen is to report the color temperature [4]. The spectral radiance of a black-body light source at a given temperature can be reported as CIE color coordinates. The white screen of a display can closely mimic a blackbody radiator and hence, its color can be reported as a color temperature. Typical color temperatures of displays range from 6000 to $10000 \mathrm{~K}$.

Gamma: To properly display an image, the luminance of the data has to change appropriately for the incoming signal [5]. The signals, which range from 0 to 255 for each color of a 24-bit display, can be adjusted by manipulating the custom colors in MS Paint. By measuring the luminance of various gray levels, gamma can be determined by fitting the data according to

$$
L(G S)=[L(W)-L(B)]\left(\frac{G S}{255}\right)^{\gamma}+L(B)
$$

where GS represents the gray level, which can range from 0 for black to 255 for white, $L(G S)$ is the luminance of a particular gray level, L(W) is the measured luminance of the display when the display is showing white and L(B) is the luminance of the display where the display is showing black. Furthermore, the students are asked to ensure that the color of the various gray levels is neutral, that is, the color as measured by the CIE color coordinates remain very close to the CIE color coordinates of the white screen.

\subsection{Typical Results of an LCD Monitor}

Data was collected using a Lenovo ThinkView monitor by a student and the results are reported in Table 2. The results are consistent with a monitor made in the middle of the last decade.

Table 2. The optical parameters of a Lenovo ThinkView monitor as measured and analyzed by a student.

\begin{tabular}{|ll|}
\hline Characteristic & $\underline{\text { Values }}$ \\
& \\
Luminance & 154 nits \\
Contrast Ratio & $915: 1$ \\
NTSC Ratio (1931 CIE Color Coordinates) & $72 \%$ \\
NTSC Ratio (1976 CIE Color Coordinates) & $88 \%$ \\
Color Temperature & $8100 \mathrm{~K}$ \\
Gamma & 2.14 \\
& \\
White (1976 CIE Color Coordinates) & $\left(\mathrm{u}^{\prime}=.189, \mathrm{v}{ }^{\prime}=.456\right)$ \\
Blue (1976 CIE Color Coordinates) & $(.146, .061)$ \\
Green (1976 CIE Color Coordinates) & $(.284, .604)$ \\
Red (1976 CIE Color Coordinates) & $(.636, .330)$ \\
\hline
\end{tabular}

Additionally, students will need to present their data in their laboratory reports in both clear language and instructive figures. Figure 1 shows the 1931 CIE Color Coordinates for the white, blue, green and red screens of the monitor as well as the NTSC triangle. Figure 2 shows the measured luminance of the different gray scales and best fit of gamma. 


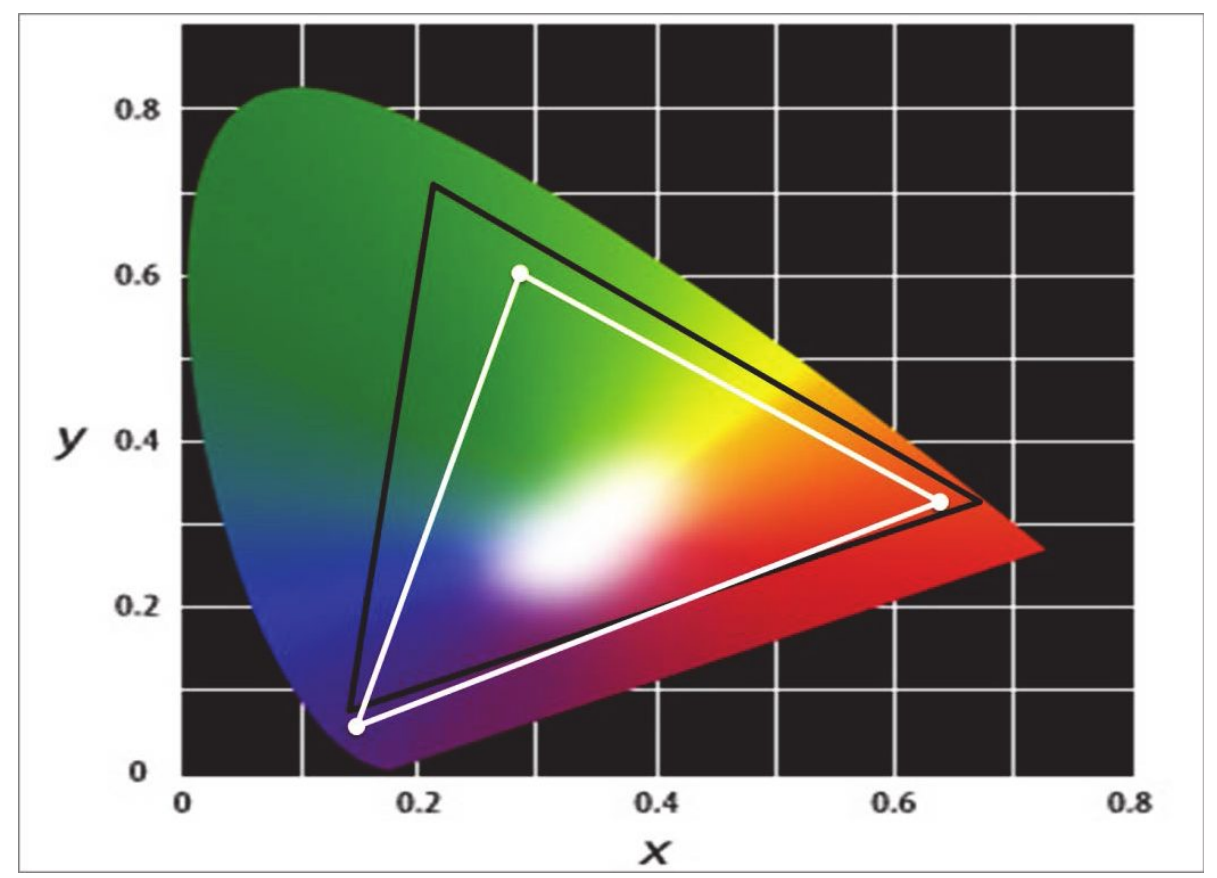

Figure 1 . The white points show the color coordinates of the three primary colors in 1931 color coordinate space, while the black triangle defines the triangle of the 3 primary colors as defined by the NTSC standards. The student has used a background image from an Adobe website to create a more compelling figure. (http://www.adobe.com/jp/support/techguides/colorPDF/colormodels/ciexyz.html)

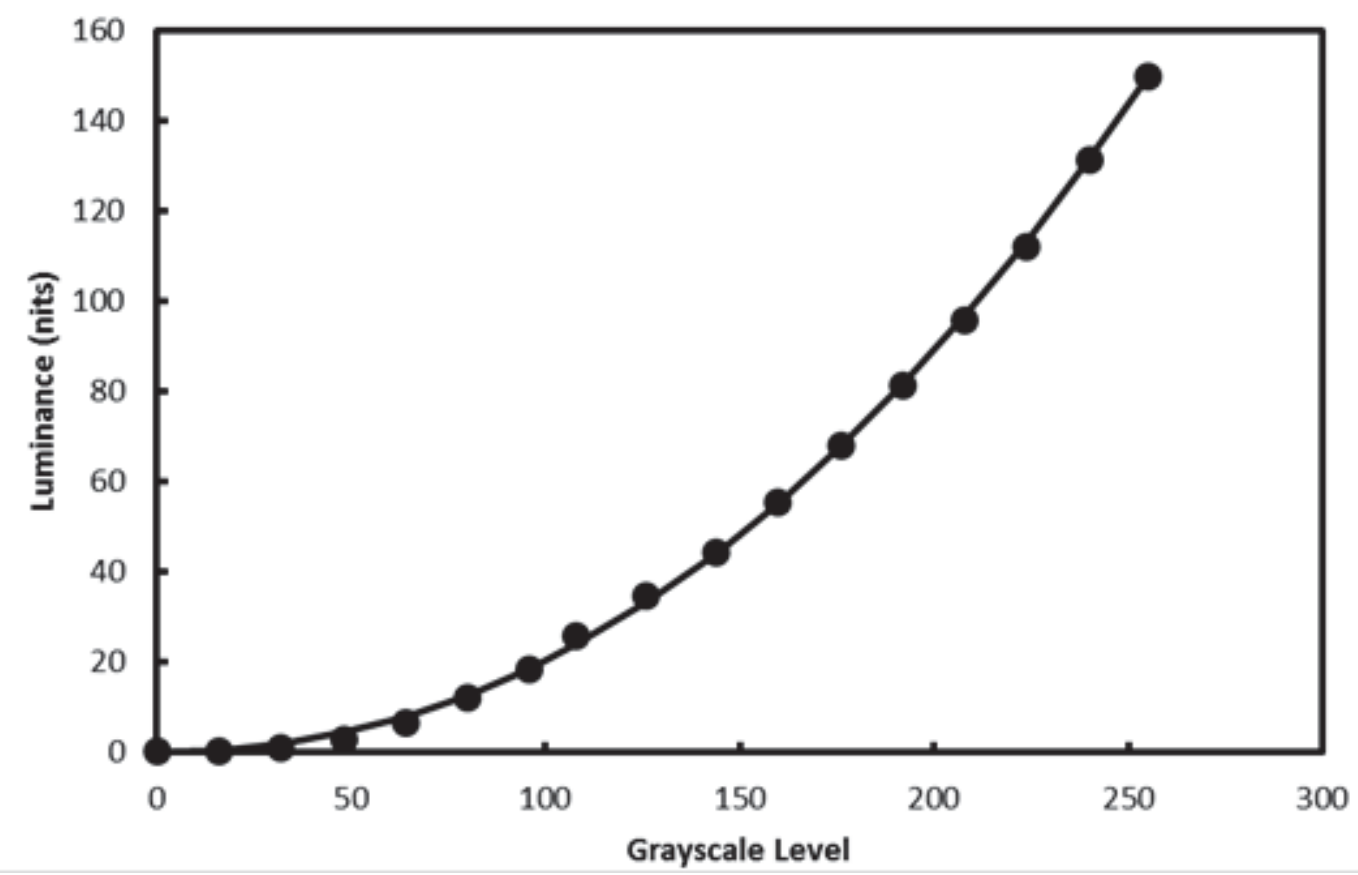

Figure 2. The luminance of the monitor is shown at different grayscale levels. The solid line shows the best fit for gamma equal to 2.14 . 


\section{OPTICAL PERFORMANCE OF A MINIATURE LIGHT BULB}

\subsection{Experimental Setup and Procedures}

Students are also asked to characterize the optical and electrical performance of a miniature light bulb. To gather the raw data needed, the students will learn how to properly use an integrating sphere [6]. The integrating sphere chosen for this work was a Labsphere 5.3" inner diameter general integrating sphere with an inner surface coating of Spectralon ${ }^{\circledR}$ material (Labsphere Product No. 4P-GPS-053-SL). The integrating sphere was chosen both for this laboratory module as well as to act as a uniform light source in another laboratory module as it has a large 2" diameter port. The light source chosen for study was a $14.4 \mathrm{~V}, 100 \mathrm{~mA}$ miniature light bulb (Radio Shack Part No. 272-1127). The light bulb is inserted into the integrating sphere for the measurements. To ensure that very little light from the source can escape the integrating sphere, two holes were drilled into a 1" port plug (Labsphere Product No. PP-100-SL) to allow for the leads for the wires needed to drive the light bulb electrically. As a result, no light can escape through an open port. To calculate the luminous flux of the light bulb, the bulb's light output must be compared against a known light source. For this purpose, we use a calibrated forward light source (Labsphere Model No. FFS-100-400 in conjunction with a power supply Labsphere Model No. LPS-150-0416). This light source can be affixed to an open port of the integrating sphere. To prevent light from either source from being incident directly upon the 'detector', a cone assembly baffle (Labsphere Product No. AS-02425-008) with a 2" diameter baffle is placed is front of the port where the 'detector' is located. Instead of using a traditional detector, a piece of opal glass (Edmunds Scientific Stock \# 43-717) is placed in a filter holder (Labsphere Product No. AS-02562-000). The experimental setup is shown in Figure 3.

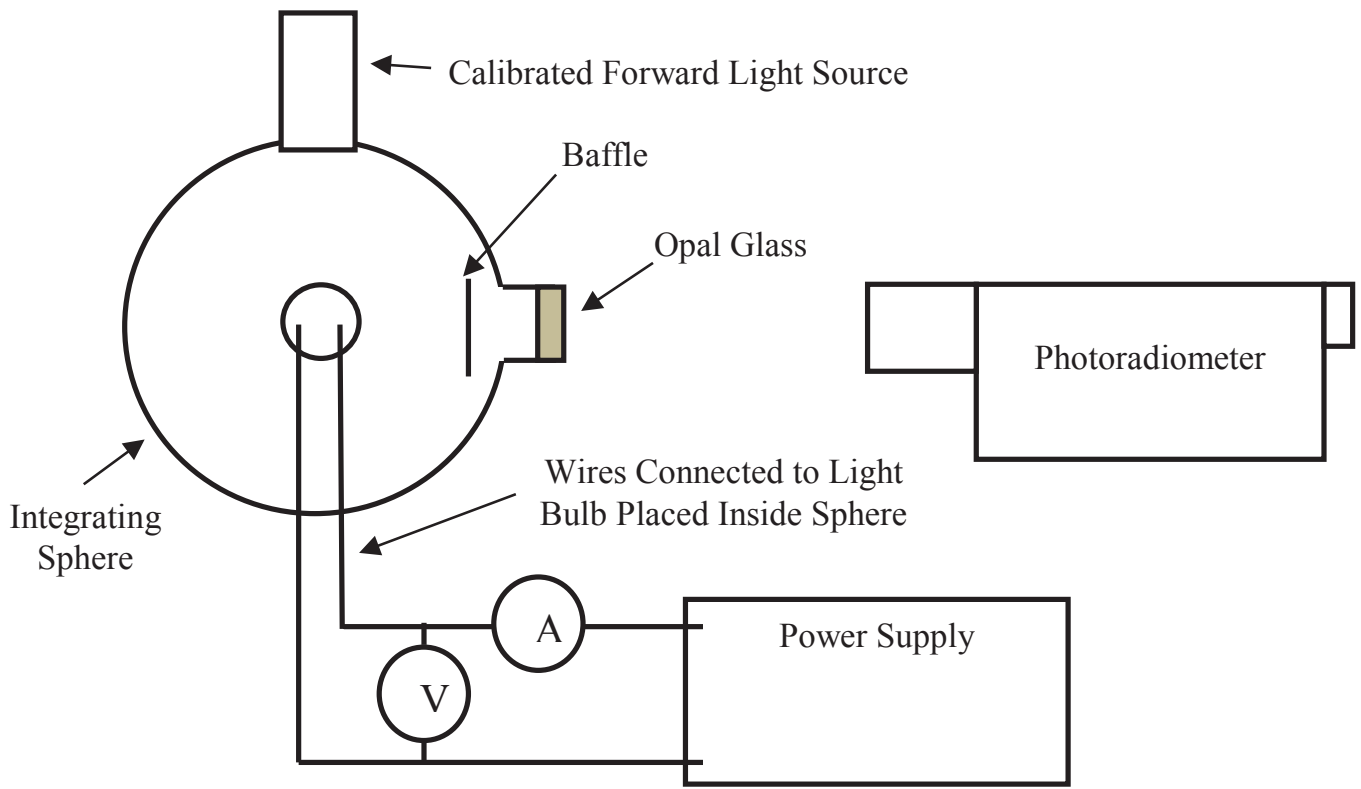

Figure 3. A side view of the experimental setup used to measure the optical and electrical properties of a miniature light bulb. A power supply is attached to wires that pass through a port plug to a light bulb inside the sphere. An ammeter and voltmeter are used to accurately measure the current through and electrical potential across of the light bulb's filament. A calibrated light source is attached to the top of the integrating sphere. A baffle is placed on the inside of the sphere to prevent both sources from directly illuminating the detector, which is a piece of opal glass. The luminance of the opal glass is measured using the photoradiometer. 
Instead of using a traditional detector, the Topcon SR-3 Photoradiometer will measure the luminance of the opal glass. With no other lights present in the room, the student will measure the luminance of the surface of the opal glass with the calibrated light source on and the light bulb off. Then, with the calibrated light source off, the student will measure the luminance of the surface of the opal glass with the light bulb on. The applied voltage to the light bulb will be varied from $0 \mathrm{~V}$ to $14.5 \mathrm{~V}$ in steps of $0.5 \mathrm{~V}$. Furthermore, the student will accurately measure the current to the light bulb as well as the applied voltage using traditional digital multimeters.

\subsection{Analysis Performed on the Light Bulb Measurements}

Once the data has been collected, students will determine the optical properties of the light bulb. The luminous flux as a function of wavelength of the calibrated light source is provided by the supplier. The luminous flux of the test light source can then be determined by [6]

$$
\Phi_{T}(\lambda)=\left(\frac{L_{T}(\lambda)}{L_{C}(\lambda)}\right) \Phi_{C}(\lambda)
$$

where $\Phi_{T}(\lambda)$ is the luminous flux of the test source as a function of wavelength, $\mathrm{L}_{\mathrm{T}}(\lambda)$ and $\mathrm{L}_{\mathrm{C}}(\lambda)$ are the measured luminance of the test and calibrated light sources as a function of wavelength and $\Phi_{C}(\lambda)$ is the luminous flux of the calibrated light source.

With this information, the luminous flux of the test source then can be determined by [7]

$$
\Phi_{v}=\sum_{\lambda=380 n m}^{780 n m} \Phi_{T}(\lambda) \mathrm{y}(\lambda) \Delta \lambda
$$

where $\Phi_{v}$ is the luminous flux of the test source, $\Phi_{T}(\lambda)$ is the luminous flux of the test source as a function of wavelength $\mathrm{y}(\lambda)$ is the $1931 \mathrm{CIE}$ color matching function. With this information, the efficacy of the light source can also be found by

$$
\eta=\frac{\Phi_{v}}{P}
$$

where $\eta$ is the luminous efficacy, $\Phi_{v}$ is the luminous flux of the test source and $\mathrm{P}$ is the electrical power used by the test source. Finally, students are asked to report the color temperature of the test source. This is usually taken directly from the reported CIE color coordinates as measured from the opal glass and neglects any impact of the integrating sphere and opal glass on the measurement. However, it is sufficiently accurate to provide information that can assist in the student's understanding of color temperature as the light bulb's spectral curve more closely resembles that of a black-body radiator.

\subsection{Typical Results of the Optical Properties of a Miniature Light Bulb}

After collecting and analyzing the data, the students will then write a formal report. Examples of the type of information presented in the report are given below. Table 3 provides an example of data collected by a student when the applied electrical potential across the light bulb was $14.5 \mathrm{~V}$. As the students also collected results over a wide range of applied voltages, the actual data can be better presented in figures, with examples of this data given here. Figure 4 shows the luminous flux as a function of applied voltage. Figure 5 shows the luminous efficacy of the light bulb measured as a function of applied power, and Figure 6 shows the color temperature as a function of applied voltage.

Table 3. Typical optical parameters of a Radio Shack miniature light bulb measured and analyzed by a student.

\begin{tabular}{|ll|}
\hline Characteristic & Values \\
& \\
Electrical Voltage & $14.50 \mathrm{~V}$ \\
Current & $103.6 \mathrm{~mA}$ \\
Luminous Flux & $10.8 \mathrm{~lm}$ \\
Luminous Efficacy & $7.17 \mathrm{~lm} / \mathrm{W}$ \\
Color Temperature & $2220 \mathrm{~K}$ \\
\hline
\end{tabular}




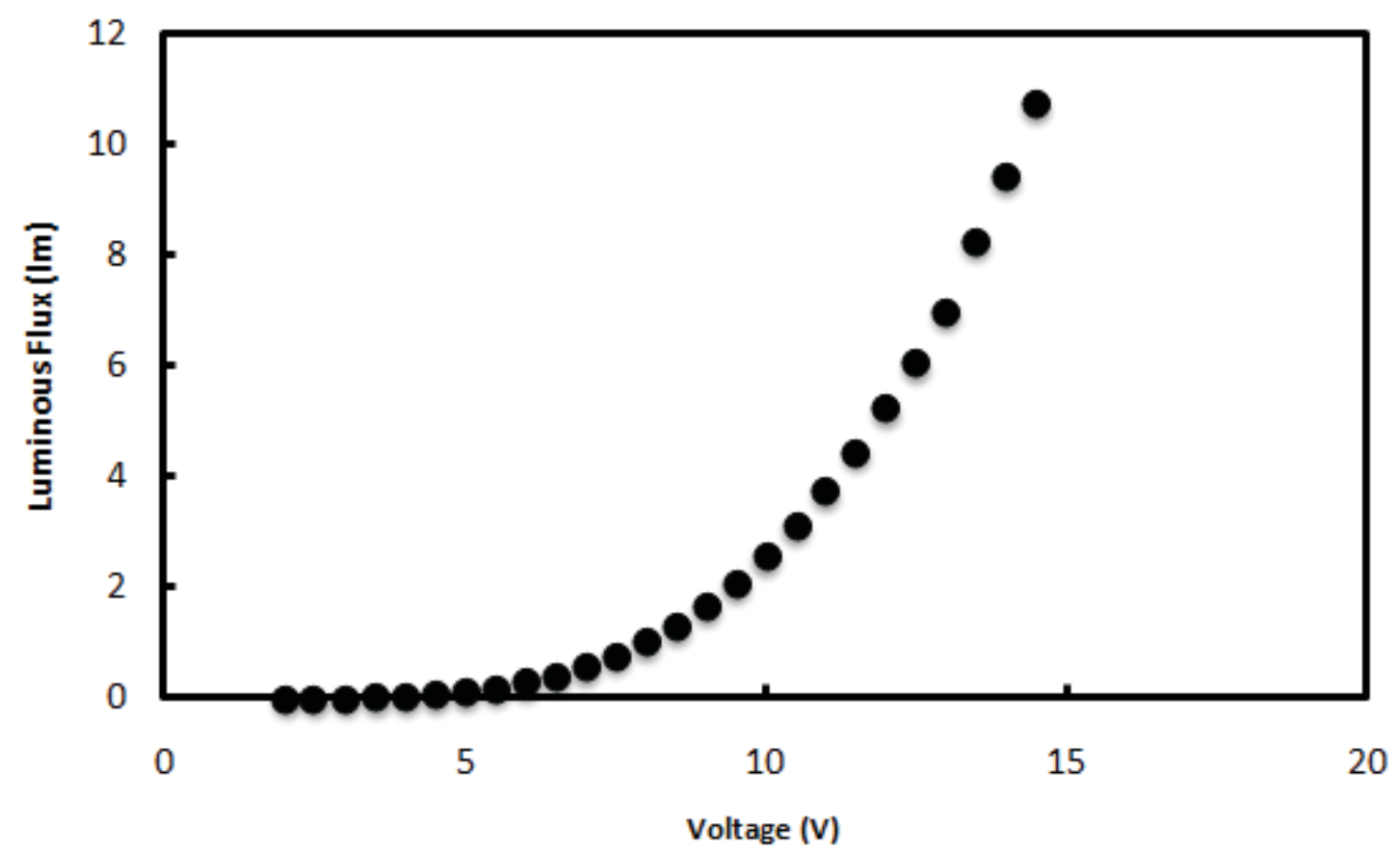

Figure 4. The luminous flux of the light bulb measured as a function of applied voltage. Note that the student collected data for electric potential less than $2 \mathrm{~V}$, but chose not to graph them because he correctly believed that the measured results were a result of background noise based on the spectrum measured by the photoradiometer.

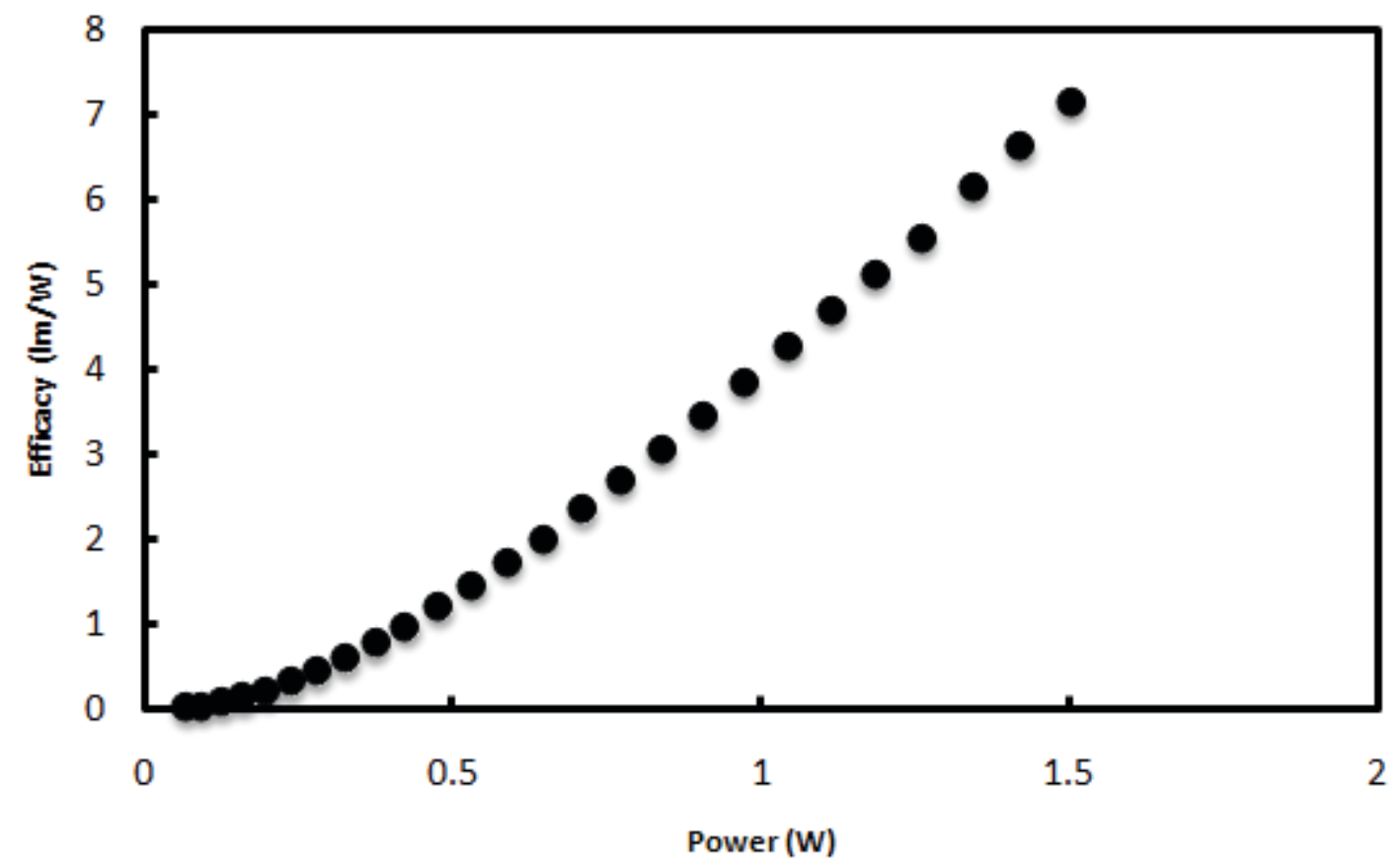

Figure 5. The luminous efficacy of the light bulb is measured as a function of applied electrical power. 


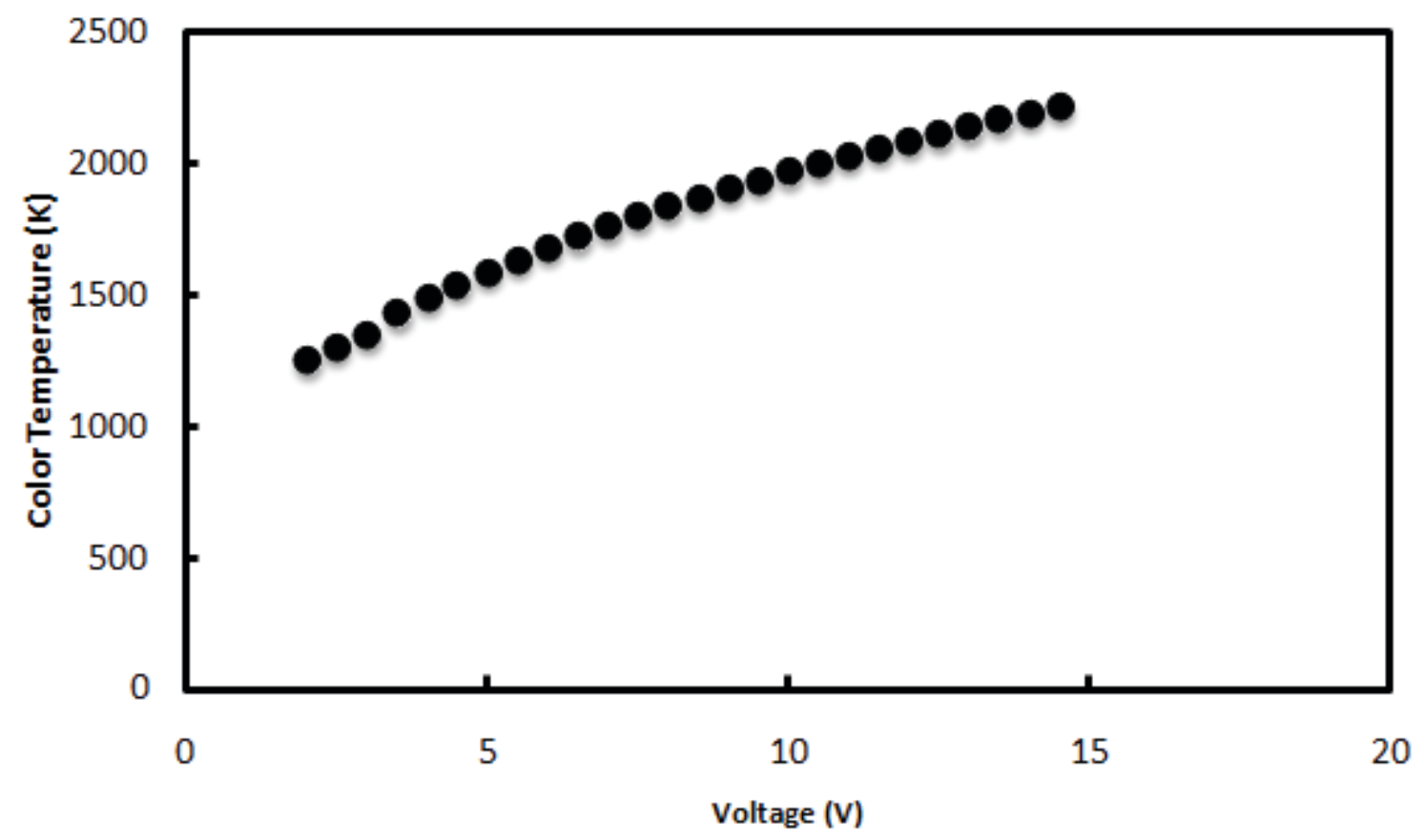

Figure 6. The color temperature of the light bulb is measured as a function of applied voltage.

\section{OPTICAL PERFORMANCE OF A FIBER OPTICS LIGHT SOURCE}

\subsection{Experimental Setup and Procedures}

Finally, the students are asked to measure the optical performance of a directional light source. Currently, we ask the student to measure the luminous intensity of a fiber optics light source (Dolan-Jenner DC950H Fiber Optic Light Source with B848 fiber optic light guide and SX5 adapter). The light of this source is quite directional and the source is set up approximately $10 \mathrm{~cm}$ from a diaphragm placed a few $\mathrm{cm}$ from an open port of the integrated sphere. The experimental set-up is shown in Figure 7. With the light directed through the diaphragm, the students will measure the luminous flux of the light passing through the diaphragm by the same methods by which they measured the luminous flux of the miniature light bulb. That is, they will measure the luminance o of the opal glass with the calibrated light source on and the fiber optic light source off, and then repeat the measurement with the calibrated light source off and the fiber light source on.

\subsection{Analysis Performed on the Fiber Optic Light Source}

The total luminous flux of the fiber optic light source entering the integrating sphere can be made by repeating the method set described in Section 3.2. When describing the light from a highly directional light source (such as a laser, LED or fiber optic light source), a more accurate description would be to measure the luminous intensity in a particular direction. The luminous intensity, $\mathrm{I}_{v}$, is given by [8]

$$
I_{v}=\frac{d \Phi_{v}}{d \Omega}
$$

where $\Phi_{v}$ is the luminous flux and $\Omega$ is the solid angle. The student will estimate the solid angle as

$$
\Omega=\frac{A}{R^{2}}
$$

where $\mathrm{A}$ is the area of the diaphragm opening and $\mathrm{R}$ is the distance from the light source to the diaphragm. 

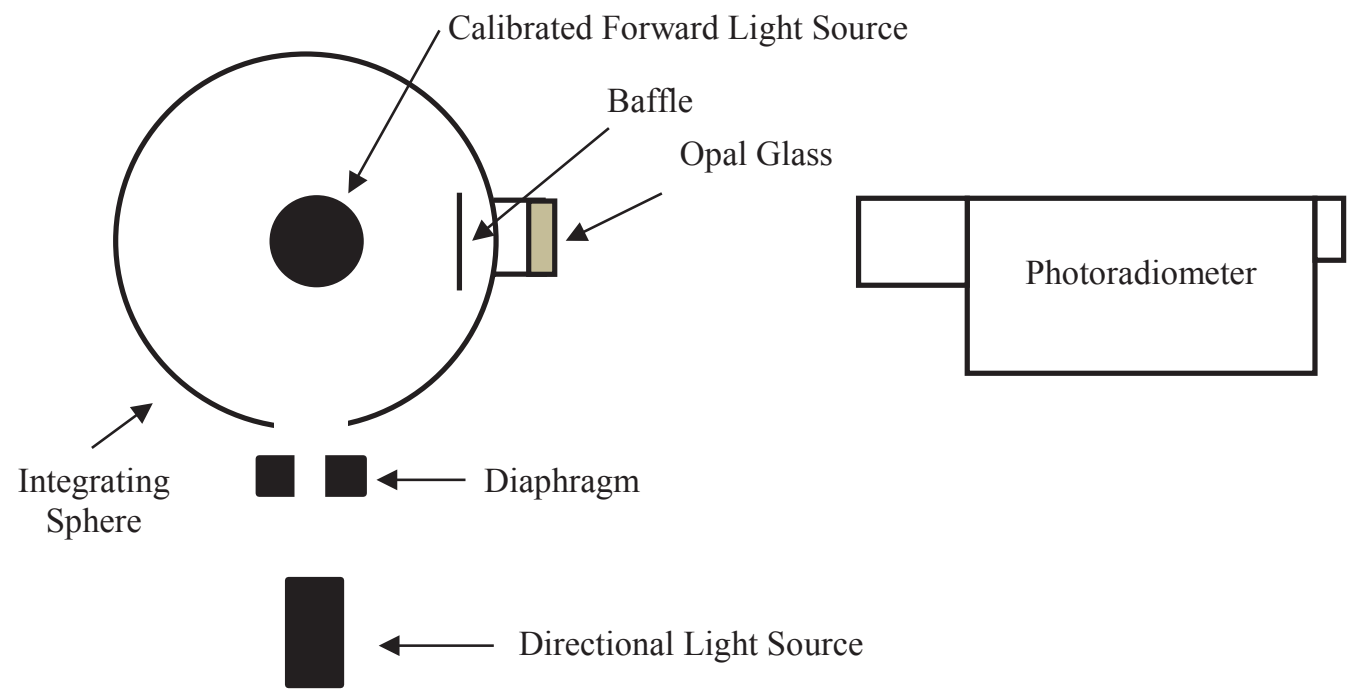

Figure 7. A top view of the experimental apparatus to measure the luminous intensity of a highly directional light source. Light from the source passes through a diaphragm into an integrating sphere, where the luminous flux can be measured by comparing the results with a calibrated light source.

\subsection{Typical Results of the Fiber Optics Source}

Again, the student is asked to perform the necessary measurement and calculations to determine the luminous intensity of fiber optics light source. Table 4 gives typical results.

Table 4. Typical optical parameters of a Dolan-Jenner fiber optic light source.

$\begin{array}{ll}\text { Characteristic } & \text { Values } \\ & \\ \text { Diaphragm Diameter } & 1.03 \times 10^{-2} \mathrm{~m} \\ \text { Diaphragm Area } & 8.45 \times 10^{-5} \mathrm{~m}^{2} \\ \text { Distance from Source to Diaphragm } & 11.2 \times 10^{-1} \mathrm{~m} \\ \text { Luminous Flux } & 2.16 \mathrm{~lm} \\ \text { Luminous Intensity } & 320 \mathrm{~cd}\end{array}$

\section{CONCLUSIONS}

This paper describes a laboratory module in the study of radiometry, photometry and colorimetry as a component of an advanced undergraduate laboratory course in Optics for physics majors. I believe that this approach to learning and the particular topic area offers a unique experience in the student's education for several reasons.

The experimental experience is closer to what a student might be faced with as either a professional engineer or scientist. The module involves correctly collecting the data but places a greater emphasis on the correct analysis of the data. In the modern laboratory, the collection of the data is often trivial compared to its correct analysis. Furthermore, by placing a significant emphasis on the correct scientific presentation of the results through the creation of a laboratory report based on American Institute of Physics Style Manual guidelines, the student must clearly articulate a deep understanding of the underlying physics as well as develop methods to succinctly express the key results in their work. 
Finally, the study of the radiometry, photometry and colorimetry is a neglected topic in most undergraduate optics courses. The study of quantitatively describing light has applications in architectural illumination, electronic displays, lighting and communications. However, the typical undergraduate optics course curriculum often has not kept up with the rapid changes in the field nor the new technologies enabled by advances in optics. As instructors, we will continue to be challenged with difficult decisions on how to present the large and broad field of optics in a single semester course and it is my belief that this highly accessible material is worthy of placement in that curriculum.

The author would like to thank the support of his colleagues, especially Dr. Asim Gangopadhyaya and Professor Thomas Ruubel in their assistance in enabling this work and participation in this conference. Furthermore, the author would also like to thank his students who have provided invaluable input on the development of this laboratory module, especially Nicholas Pflederer, David Haberkorn, Philip Dluhy and Shelby Grzetic. Finally, the author would like to thank the technical support from Labsphere Corporation for their assistance in formulating a solution to use the photoradiometer in conjunction with an integrating sphere.

\section{REFERENCES}

[1] “Bachelor's-Only Departments Averaging 10 or More Physics Bachelor's Degrees Per Year, Classes of 2008 through 2010", American Institute of Physics, n.d. <http://www.aip.org/statistics/trends/highlite /edphysund/table4e.htm> (11 June 2013).

[2] Bahadur, B., in Liquid Crystals: Applications and Uses, Vol. 2, edited by B. Bahadur (World Scientific, Singapore, 1991), pp. 75-80.

[3] U.S. Federal Communications Commission, TV Transmission Standards. Washington Government Printing Office, October, 2012 (47 CFR §73.682).

[4] Bahadur, B,. in Liquid Crystals: Applications and Uses, Vol. 2, edited by B. Bahadur (World Scientific, Singapore, 1991), pp. 61.

[5] Poynton, C., Digital Video and HDTV, $1^{\text {st }}$ Ed. (Elsever, San Francisco, 2003), pp. 257-261.

[6] Technical Guide: A Guide To Integrating Sphere Radiometry and Photometry, Labsphere, $<\mathrm{http} / /$ www.labsphere.com/uploads/technical-guides/a-guide-to-integrating-sphere-radiometry-andphotometry.pdf> (13 June 2013).

[7] Bahadur, B., in Liquid Crystals: Applications and Uses, Vol. 2, edited by B. Bahadur (World Scientific, Singapore, 1991), pp. 29, 39-51.

[8] DiMarzio, C. A., Optics for Engineers, $1^{\text {st }}$ Ed. (CRC Press, 2012), pp. 361-380. 